\title{
LIES MATTER
}

(Accepted 22 November 2018)

Normative legal philosophy primarily concerns itself with the task of understanding which weighty reasons should guide our legal institutions. In order to make sense of these reasons, we must pursue a certain amount of conceptual analysis. Concepts allow us to make sense of our reasons. This is as true in law as it is elsewhere in the normative landscape.

At a time when politicians on both sides of the Atlantic are challenging the role of epistemic authorities and factual claims in democratic decision-making (through reference to 'alternative facts', 'fake news', and other objectionable propositions), the analysis of the legal status of false and misleading claims is extremely important. By clarifying the status of truth and falsity in civil discourse, philosophers can make a real and significant contribution to the upkeep of the norms of civil society. The stakes of such discussion are high.

Seana Shiffrin's recent and important book, Speech Matters, contributes to this exercise in a clear, compelling, and innovative manner. It begins with a simple problem. We must form a mutual understanding of the circumstances that we share with fellow moral agents in order to cooperate and live minimally decent lives. Ensuring that our interactions are respectful requires knowledge of our fellow citizens' thoughts, beliefs, feelings, and needs. Without this knowledge, we cannot ensure the aptness of our moral judgements.

This knowledge is especially important in coercive contexts. The freedom-restricting nature of coercion ensures that morally appropriate laws must be sensitive to these factors. Our ability to discharge our moral, political, and legal duties depends on possessing the knowledge required to form the mutual understanding necessary for cooperation. Yet, this knowledge is difficult to obtain because we can 
only guess and infer from the behaviour of other moral agents which thoughts, beliefs, feelings, and needs they hold dear. This basic hurdle to fulfilling the requirements of morality gives the spoken word critical importance as the most precise and authoritative mechanism through which we can convey our mental content to each other. In short, morality requires us to share ourselves with others.

Lies and deception both obstruct this process in different ways. Whereas the folk intuition suggests that lying is wrong when it deceives, Shiffrin's argument begins by separating out these two notions and suggesting that they each pose different obstructions to the moral community. According to Shiffrin, a lie is an intentional assertion by $\mathrm{A}$ to $\mathrm{B}$ of a proposition $\mathrm{P}$ such that:

1. A does not believe $\mathrm{P}$, and

2. A is aware that $\mathrm{A}$ does not believe $\mathrm{P}$, and

3. A intentionally presents $\mathrm{P}$ in a manner or context that objectively manifests A's intention that $\mathrm{B}$ is to take and treat $\mathrm{P}$ as an accurate representation of A's belief. ${ }^{1}$

Crucially, P need not be false. Although A need not believe P, A need not believe $\mathrm{P}$ to be false either. Rather, A can remain agnostic about the truth of P. Because of this, Alice does not need to intend to deceive Brian when she lies to him. Although many lies do deceive, the success of a lie remains independent of Alice's persuasiveness or Brian's credulity at Alice's assertion. Lies can evade the truth rather than establish falsehood.

This difference ensures that lies differ from deceit in (at least) three ways:

a) Deception must impart a false belief or confirm a pre-existing false belief, whereas a lie need not affect B's mental content at all.

b) B must believe a successful deceptive proposition but need not believe a successful lie.

c) Deception need not involve speech acts but lying must.

\footnotetext{
${ }^{1}$ Seana Valentine Shiffrin, Speech Matters: On Lying, Morality, and the Law (Princeton: Princeton University Press, 2014), p. 12.
} 
Shiffrin's claim that lies and deception are two compatible but distinct phenomena is commendable and follows a growing trend in the philosophical literature. ${ }^{2}$ On this view, lying is a form of speech that changes our discursive circumstances rather than necessarily transmitting false beliefs to others. ${ }^{3}$ Cases where lies and deceit come apart include:

Pure Lies - A may lie by asserting what A mistakenly believes to be false (and yet happens to be true). ${ }^{4}$

Bald-Faced Lies - A may lie by asserting to B something that both parties know is false. ${ }^{5}$

Knowledge-Lies - A may lie by asserting to B something that makes it more difficult for B to know the truth (but need not lead B to believe a falsehood) ${ }^{6}$

These cases cast doubt on the folk intuition and reveal the relationship between lies and deception to be more complex than commonly assumed. In this article, I offer two comments on Shiffrin's explanation of the distinct wrongfulness of lying: First, I'll summarise Shiffrin's explanation of the wrong-making features of lying and suggest that it may possess broader explanatory power as it can explain the wrongfulness of other objectionable speech acts. Second, I'll consider Shiffrin's explanation of when it is permissible to misrepresent ourselves to others and contend that she is too quick to reject alternatives to her view.

\footnotetext{
${ }^{2}$ Examples of this trend include: Thomas Carson, 'The Definition of Lying', Noûs 40 (2006): 284306; Roy Sorensen, 'Bald-faced Lies! Lying Without the Intent to Deceive', Pacific Philosophical Quarterly 88 (2007): 251-64; Don Fallis, 'What is Lying?', Journal of Philosophy 106 (2009): 29-56; Thomas Carson, Lying and Deception: Theory and Practice (Oxford: Oxford University Press, 2010); Roy Sorensen, 'Knowledge-lies', Analysis 70 (2010): 608-15; Jennifer Saul, Lying, Misleading, and What is Said (Oxford: Oxford University Press, 2012): 8-10; Andreas Stokke, 'Lying and Asserting', Journal of Philosophy 110 (2013): 33-60. For criticism, see Jennifer Lackey, 'Lies and Deception: An Unhappy Divorce', Analysis 73 (2013): $236-48$.

${ }^{3}$ For example, Roy Sorensen labels both bald-faced lies and knowledge-lies as forms of 'Conversational Cheating', Sorensen, 'Knowledge-lies', p. 614.

${ }^{4}$ Shiffrin, Speech Matters, p. 116.

${ }^{5}$ Carson, 'The Definition of Lying', p. 290; Sorensen, 'Bald-faced Lies!'; Don Fallis, 'Are Bald-Faced Lies Deceptive After All?', Ratio 28 (2015): 81-96. For criticism, see Patrick Leland, 'Rational Responsibility and the Assertoric Character of Bald-Faced Lies', Analysis 75 (2015): 550-54.

${ }^{6}$ Sorensen, 'Knowledge-lies'. Whether knowledge-lies are actual lies appears more controversial than pure lies or bald-faced lies. For criticism, see Julia Staffel, 'Reply to Roy Sorensen, 'KnowledgeLies', Analysis 71 (2011): 300-02.
} 


\section{THE WRONGFULNESS OF LYING}

Shiffrin argues that the importance of speech in facilitating cooperation with our fellow moral agents can ground a moral duty to promote truthful understanding and a default presumption in favour of truthful communication. This duty often encompasses requirements of sincerity (believing what we say) and accuracy (taking reasonable steps to avoid falsehood and misunderstanding). ${ }^{7}$ Lies and deception both contravene this duty in different ways: 'Deception is wrong because it unduly hazards the false for the deceiver's own purposes, whereas lying is wrong because it places the certainty of truth out of reach for the liar's own purposes' ${ }^{8}$

The wrong of deception hinges on the violation of a duty to take care not to cause others to form false beliefs based on our behaviour. When this duty exists, deception is wrong. In contrast, the wrong of lying hinges on the fact that it operates on a maxim that, if universalised, would deprive us of crucial truths and a central method of distinguishing truth from falsehood. When we lie, we risk undermining our most trustworthy method of learning the thoughts, beliefs, feelings, and needs of our fellow moral agents. We require this information for mutual understanding and cooperation, and these are compulsory moral aims. So, lying threatens to obstruct full moral relations, and by doing so, wrongs the listener, the speaker, and humanity at large. ${ }^{9}$

This explanation of the wrong of lying resembles a discursive failure of moral-recognition respect. ${ }^{10}$ Lying obstructs full moral relations with other agents by preventing us from establishing the understanding required to cooperate respectfully. Lying is symptomatic of a form of disrespect for the status of ourselves and others as equal moral agents. Because of this, each lie symbolises a failure to respect the moral equality mandated by our capacity for agency:

My basic argument is that the fundamental responsibility to secure and protect the individual and social conditions under which we possess [moral] agency and under which we may understand and acquit our moral duties exerts a lexical priority. To satisfy this responsibility, our reasons for action must take a form that, if known and regarded as permissible, would maintain

\footnotetext{
${ }^{7}$ Shiffrin, Speech Matters, p. 11.

${ }^{8}$ Ibid, p. 23.

${ }^{9}$ Ibid, pp. 23-4.

${ }^{10}$ Stephen Darwall, 'Two Kinds of Respect', Ethics 88 (1977): 36-49.
} 
the epistemic conditions and presumptions that enable successful moral agency, rather than jeopardising them, calling them into question, or rendering their existence merely accidental. ${ }^{11}$

By characterising the wrong of lying as a discursive obstruction to the moral community, Shiffrin's argument achieves an important goal. It explains the specific wrong of lying through a broader explanation of the wrongfulness of a species of disruptive objectionable speech acts. I suggest that this explanation of the wrong-making features of lying should be of broad interest because, if proved plausible, it may also explain the wrongfulness of other objectionable forms of speech that threaten to obstruct social relations.

To see this, consider the problem of 'silencing' or subordinating speech. ${ }^{12}$ Suppose that A is silenced when B speaks in a manner that makes it more difficult:

(1) For A to voice A's own opinion freely, and/or

(2) For A's opinion to receive a fair hearing, and/or

(3) For A to voice A's opinion without risk of being deliberately misunderstood.

Alice can be silenced either by Brian enforcing formal rules that restrict her opportunities to converse with her fellow interlocutors (e.g., strict exclusionary rules) or by Brian perpetuating norms that undermine the apparent sincerity of Alice's speech (e.g., slurs or stereotypes). Both forms of behaviour offer Brian ways of preventing Alice from communicating as she wishes. ${ }^{13}$

Explaining why such actions are wrongful is a tricky business. Clearly, silencing can harm. ${ }^{14}$ However, proof of the causation of harm from individual speech acts is difficult. Not every act that silences must harm because not every instance of communication benefits. While it is true that the capacity for communication generally benefits (and so silencing generally harms), explaining the distinctive wrong of each individual silencing act in terms of harm is difficult. Non-consequentialists find this instrumental explanation

\footnotetext{
${ }^{11}$ Shiffrin, Speech Matters, p. 26.

${ }^{12}$ I intend the following brief definition to be reasonably ecumenical between competing definitions of this complex phenomenon.

${ }^{13}$ Rae Langton, 'Speech Acts and Unspeakable Acts', Philosophy \& Public Affairs 22 (1993): 293-330; Jennifer Hornsby, 'Disempowered Speech', Philosophical Topics 23 (1995): 127-47; Ishani Maitra, 'Silencing Speech', Canadian Journal of Philosophy 39 (2009): 309-38. For a recent summary, see Wesley Buckwater, 'Epistemic Injustice in Social Cognition', Australian Journal of Philosophy, Online First: 1-15, pp. 3-5.

${ }^{14}$ J.S. Mill, On Liberty (Oxford: Oxford University Press, 1991 [1859]): p. 21.
} 
unsatisfying. Thus, it is common to look elsewhere to discover a non-instrumental explanation of the wrongfulness of silencing. ${ }^{15}$

However, we cannot simply appeal to freedom of speech to provide non-harm-based reasons against silencing. It might appear tempting to characterise silencing as a rights-violation by claiming that silencing infringes the speaker's right to freedom of speech. However, the difficulty with this argument is that the right in question must incur a positive duty on the listener to be heard on fair terms. In order for the rights-violation argument to encompass anything more than (1), the meaning of Alice's speech must also be recognised as worthy of protection. Our right to free speech must protect speech as more than mere locution. ${ }^{16}$

Without this recognition, Brian does not contravene Alice's right to speak freely if he consistently dismisses the meaning of her words out of hand, perpetually misconstrues her phrasing, or intentionally misunderstands her speech for reasons other than her speech's content (e.g., because of her gender, race, or age). When Brian acts in this way, he silences Alice by undermining the meaning of her words without preventing her actual acts of expression. Such actions are disrespectful even when they don't directly harm Alice. If we want the rights-violation explanation of silencing to satisfactorily account for this pernicious behaviour, then our right to free speech must protect both intended meaning and literal speech. Establishing that the right to free speech can be consistently characterised in this way without threatening to become overly demanding remains a significant controversy. ${ }^{17}$ Specifically, we need to know how much discursive uptake and communicative reciprocity our rights to free speech can demand of listeners.

\footnotetext{
${ }^{15}$ One prominent example of this trend is Miranda Fricker's Kantian notion of 'Epistemic Objectification'. Miranda Fricker, Epistemic Injustice (Oxford: Oxford University Press, 2007), chpt. 6. There is an interesting family resemblance between Fricker's and Shiffrin's arguments grounded in respect for the discursive standing of individuals as epistemic and moral agents.

${ }^{16}$ Jennifer Hornsby and Rae Langton, 'Free Speech and Illocution', Legal Theory 4 (1998): 21-37.

${ }^{17}$ Catherine MacKinnon, Feminism Unmodified (Cambridge, Mass.: Harvard University Press, 1987); Rae Langton, 'Whose Right? Ronald Dworkin, Women, and Pornographers', Philosophy \& Public Affairs 19 (1990): 311-59; Catherine MacKinnon, Only Words (Cambridge Mass.: Harvard University Press, 1993); Langton, 'Speech Acts and Unspeakable Acts'; Daniel Jacobson, 'Freedom of Speech Acts? A Response to Langton', Philosophy \& Public Affairs 24 (1995): 64-79; Hornsby and Langton, 'Free Speech and Illocution'; Ronald Dworkin, 'Women and Pornography', The New York Review of Books (21 October 1993); Leslie Green, 'Pornographizing, Subordination and Silencing', in R.C. Post (ed.) Censorship and Silencing: Practices of Cultural Regulation (Los Angeles: The Getty Research Institute, 1998): 285-312; Lorna Finlayson, 'How to Screw Things with Words', Hypatia 29 (2014): 774-89.
} 
So, a gap needs to be filled. We need an explanation of the intrinsic wrong of silencing that does not simply reduce to harm and an explanation of the reciprocal moral demands of discourse to inform our free speech rights. I suggest that Shiffrin's Kantian argument concerning the obstruction of moral relations between agents (and her subsequent 'Thinker-Based' approach to free speech') appears well suited to this task.

Silencing, like lying, deprives the target of the full status of a moral agent. Silencing, like lying, strips the target of discursive tools required to participate fully in the moral community. Silencing, like lying, fails to acknowledge the value of our collective ends. Finally, silencing, like lying, threatens our mutual understanding that underpins the moral community. Thus, silencing shares significant wrong-making features with lying when we view lying from Shiffrin's perspective. Silencing also fails the same moral test: A universalised maxim that permits the unjustified silencing of particular groups or individuals would deprive us of forms of respectful discourse that are owed to other agents. Specifically, the reasons for such action will not '.. take a form that, if known and regarded as permissible, would maintain the epistemic conditions and presumptions that enable successful moral agency.... ${ }^{18}$

Of course, lying and silencing are two distinct phenomena. For example, they differ in that lying makes it more difficult to tell truth from falsity, whereas silencing makes it more difficult to be heard and understood as we intend. Furthermore, lying invites and abuses trust whereas silencing merely erodes it. ${ }^{19}$ These differences explain the differing content and demandingness of the preventative duties corresponding to each act. However, both phenomena threaten our capacity to form a mutual understanding with our fellow moral agents. As a result, I suggest that Shiffrin's explanation of why nondeceptive lying is wrong may play some role in explaining our duties concerning other forms of objectionable speech. By providing a satisfying general explanation of the wrongful nature of these forms of speech, Shiffrin's argument can offer important Kantian insights to debates aside from those over the legal status of lying.

\footnotetext{
${ }^{18}$ Shiffrin, Speech Matters, p. 26.

${ }^{19}$ Collin O’Neil, 'Lying, Trust, and Gratitude', Philosophy \& Public Affairs 40 (2012): 301-33. Thanks to an anonymous reviewer for drawing this difference to my attention.
} 


\section{THE PERMISSIBILITY OF MISREPRESENTATION}

I have suggested that Shiffrin's account of lying is broadly compelling and that her respect-based explanation of the wrongfulness of lying may extend to explain the wrongs of other types of objectionable, disruptive, and subordinating speech. This is a strength of the general nature of her view. By explaining the narrow wrong of lying as an instance of a broader moral wrong (obstructing moral relations), Shiffrin opens her argument to being extended to other forms of speech that commit the same wrong in different ways. In this section, I turn to consider her related claims concerning the permissibility of intentionally misleading wrongdoers (such as Kant's famous Murderer-at-the-Door).

Shiffrin argues that it is permissible to lie to another moral agent when we find ourselves in a morally justified suspended context - a context where '...the normative presumption of truthfulness is suspended because these contexts serve other valuable purposes whose achievement depends upon the presumption's suspension and the fact and justification of the suspension are publicly accessible. ${ }^{20}$ Such contexts transform an objectionable lie into a justified falsification by negating the third condition of Shiffrin's definition of a lie:

3. A intentionally presents $\mathrm{P}$ in a manner or context that objectively manifests $A$ 's intention that $B$ is to take and treat $\mathrm{P}$ as an accurate representation of A's belief.

Therefore, the moral justification of suspending the context within which Brian may treat $\mathrm{P}$ as an accurate representation of Alice's belief is where we must concern ourselves. The most plausible explanation of this justification will explain when we are justified in misleading others. Although we will mislead in these circumstances, we will not lie because the misled will have no morally justified reason to expect the truth from us.

Shiffrin's explanation of justifiably suspended contexts centres on the content of what we intend to misrepresent. ${ }^{21}$ If the content of our lie would further the listener's destruction of the moral community, then we may permissibly misrepresent our beliefs to them without fear of wronging them (as we would if we had lied to them). This is

\footnotetext{
${ }^{20}$ Shiffrin, Speech Matters, p. 16.

${ }^{21}$ Ibid, pp. 32-7.
} 
because the intended aim of the listener's immoral action justifiably suspends the context within which she may reasonably expect to hear the truth from the speaker.

The limits of permissible misrepresentation are set by the requirement that we respect the listener's agency by ensuring the possibility of moral redemption and their return to a more truthful context. No agent should be cast out of the moral community permanently and truthful speech plays an important part in both learning from our moral mistakes and participating with our fellow moral agents. ${ }^{22}$ The problem that Shiffrin is trying to avoid is that the wrongdoer becomes stranded in a truth-free zone:

One thematic way to put what troubles me about the idea that the murderer becomes a truthfree zone is that, were it a rule, it would place him in something like solitary confinement, without reliable access to a decent means of understanding the external world and human relations, and, further, without a compass for finding the exit ... Placing someone in this predicament, I think, is inconsistent with continuing to see him as a member of the moral community, albeit one of poor standing. ${ }^{23}$

In these circumstances, truthfulness becomes a type of 'White-Flag' convention that we rely on in times of vulnerability in order to maintain ways of escaping discursive conflict. Lies and misrepresentation both make it more difficult for the listener to distinguish truth from falsehood. As a result, both phenomena threaten to isolate us from the moral community. The main difference between the two is that misrepresentation occurs in a justified suspended context. This permits us to treat the listener in a way that would otherwise be objectionable. However, being treated in this way still threatens isolation, and this isolation is inconsistent with the respect due to our fellow moral equals. Thus, permissible misrepresentation has a limiting threshold below which we cannot sink for fear of isolating the listener.

Shiffrin argues that her substantive 'Content-Based' argument is more plausible than its competitors. However, I am concerned that she dismisses procedural alternatives to her content-based approach too quickly. Rather than linking the permissibility of misrepresentation to the content of what is said, procedural explanations of the permissibility of misleading rely on the notion of reciprocity to argue that: 'Because the wrongdoer does not follow the rules, the general rules do not apply to him and therefore, we can lie in order to

\footnotetext{
${ }^{22}$ Ibid, p. 39.

${ }^{23}$ Ibid, p. 38.
} 
constrain him, not because of the content of our misrepresentation but because his interactions with and among us do not comply with the rules that render him eligible for truthful communication.... ${ }^{24}$

Shiffrin dismisses proceduralism for being fatally over-inclusive and cites the white-flag worry of isolation as a motivating concern. ${ }^{25}$ She is concerned that lying to liars merely because they have lied to us will lead us all too easily into a truth-free zone of no return. But this dismissal is too quick. It does not follow from the adoption of procedural rules that such an account cannot limit the sorts of misrepresentation it permits nor prevent the isolation of listeners. Although Shiffrin has a particular interpretation of Kant in mind here, there is a range of possible forms of proceduralism we could adopt. ${ }^{26}$ Crucially, a procedural explanation that rejects the substantive content-based approach but accepts constraints grounded in the requirements of respect (including avoiding the harms of epistemic isolation) remains open.

This is because we can construe respect for moral agents in procedural as well as substantive terms. Such a view could accept similar limits as a content-based approach but would link the wrongfulness of misrepresentation to set of procedural rules of truthtelling that are required by a well-functioning moral community. If an agent breaks those rules, then others may also do so in order to avoid harm in the short term and bring that individual back in line with the requirements of membership of the moral community in the long term. As one possible example, consider a form of discursive right-forfeiture where liars forfeit their rights against being misled when they lie to other agents. ${ }^{27}$ So long as the wrongdoer in question is aware of the 'rules of the communication game' and the possibility of reciprocal misleading, then it is compatible with respect for them as an epistemic peer that we hold them responsible for their lies in this way.

\footnotetext{
${ }^{24}$ Ibid, pp. 31-2.

${ }^{25}$ Ibid, pp. 30-2.

${ }^{26}$ Tamar Schapiro', Kantian Rigorism and Mitigating Circumstances' Ethics 117 (2006): 32-57.

${ }^{27}$ Christopher Heath Wellman, 'The Rights Forfeiture Theory of Punishment', Ethics 122 (2012): 371-93; Christopher Heath Wellman, Rights Forfeiture and Punishment (Oxford: Oxford University Press 2017). For criticism, see Massimo Renzo, 'Rights Forfeiture and Liability to Harm', Journal of Political Philosophy 25 (2017): 324-42.
} 
Procedural approaches of this kind may simply provide a different route to a similar end as Shiffrin's own content-based approach. Both views would function to protect the moral community in their own ways. ${ }^{28}$ We need not deny this similarity to criticise proceduralism. For it may be the case that there is something particularly offensive about lying to liars in order to make them tell the truth which means that it is an ineffective tool for enforcing norms of truthfulness. Alternatively, we might worry that the hypocrisy involved in such interactions is fundamentally inconsistent with the aims of returning liars to the moral community. If either of these worries were the case, then procedural arguments would be an unattractive route to take. But these are not the sorts of objections that Shiffrin offers against proceduralism. Rather, it is the worry about escalation and the loss of white flag conventions that motivates her dismissal of the view, and this worry seems unfounded given the breadth of possible procedures that might be adopted.

There is nothing prima facie inconsistent with a procedural approach adopting constraints to prevent escalation and isolation. Such constraints could prevent reciprocal lying from escalating to create a truth-free zone because this consequence will prevent them from achieving their goal of returning wrongdoers to the moral community. If the purpose of the reciprocal breach of the relevant truth norms is to return others back to playing by the rules of the communal game, then isolation would hinder this purpose. Such escalation would be self-defeating. ${ }^{29}$

Sadly, investigating the further details of this family of views is a task for another time. In this brief discussion, I hope to have explored the possible strengths and weaknesses of Shiffrin's compelling work on the wrong of lying, and I welcome further discussion in our attempts to understand the normative importance of lying in both morality and law.

\footnotetext{
${ }^{28}$ C.f. Procedural and substantive accounts of democracy.

${ }^{29}$ For example, proceduralists could take the white flag analogy very seriously and look to establish 'just war' rules of discursive distinction, necessity, and proportionality to govern reciprocal misleading, just as they govern reciprocal harm in conflict. Although in war we are permitted to harm unjust attackers, this does not mean that there are no limits to the harm that we can impose. Proceduralists could conceive of similar rules for lying. Such rules would ensure that white flags still hold weight on the discursive battlefield.
} 


\section{ACKNOWLEDGEMENTS}

I would like to thank George Letsas for organising the conference at which this comment was presented, and Seana Shiffrin for her insightful response to my concerns. I would also like to thank Kate Greasley, Jeff Howard, Emily McTernan, Tom Parr, Prince Saprai, Kartik Upadhyaya, and an anonymous reviewer for their insights and comments.

\section{OPEN ACCESS}

This article is distributed under the terms of the Creative Commons Attribution 4.0 International License (http:/ / creativecommons.org/licenses/ by/4.0/), which permits unrestricted use, distribution, and reproduction in any medium, provided you give appropriate credit to the original author(s) and the source, provide a link to the Creative Commons license, and indicate if changes were made. 